Handbuch der Physik

Herausgegeben von S. Flügge. Band 2: Mathematische Methoden, 2. Pp. vii +520. (Berlin : Springer-Verlag, 1955.) $88 \mathrm{D}$. marks.

$\mathrm{T}$ HIS is a valuable compendium of methods of mathematical physics which, while in no way threatening the pre-eminence of "Courant-Hilbert" and "Jeffreys and Jeffreys", makes its own selection of material and thus contains some valuable techniques which are absent from those standard works. It is stronger, particularly, on algebraical and geometrical methods. A fairly substantial account of the theory of groups (including group representation), rings, fields, ideals and linear algebras, with indications of fields of their application, is given first. It is followed by an account of analytical geometry, differential geometry and field theory, Riemann geometry, tensors, spinors, and canonical transformations. Next follows the longest section-functional analysis, by Prof. I. N. Sneddon; this section is in English, whereas the rest of the book is in German. He begins with a synopsis of Banach space theory and then goes on to a rather full account of integral transforms, including the Laplace, Fourier, Mellin and Hankel transforms, and various finite transforms such as the Legendre transform and other transforms arising from equations of Sturm-Liouville type. This section concludes with an account of operators in Hilbert space and Schwartz's theory of distributions.

The following, and second longest, section of the book is a fairly full account of numerical and graphical methods, which though on conventional lines contains many useful tips about practical procedure. Half this section is devoted to initial-value, boundary-value and eigen-value problems for ordinary and partial differential equations and to integral equations and functional equations. The book concludes with a rather brief account of modern computing machines of both the analogue and digital types. There are subject indexes, both in English and in German.

Like "Courant-Hilbert", the book will perform its most useful service by introducing to applied mathematicians a number of techniques which they are apt sometimes to regard (erroneously) as proper only to investigations in pure mathematics. A copy could usefully be purchased for any mathematics or physics library.

M. J. LIGHTHILL

\section{Thermodynamics and Statistical Mechanics}

By Arnold Sommerfeld. (Lectures on Theoretical Physics, Vol. 5.) Translated by J. Kestin. Edited by F. Bopp and J. Meixner. Pp. xviii +401. (New York: Academic Press, Inc.; London: Academic Books, Ltd., 1956.) 7 dollars.

COMMEREELD died before completing this present S volume of his theories on theoretical physics, but he had done a good deal of the work and the plan of the rest was clear enough for Profs. Bopp and Meixner to complete it, following as closely as possible the author's intention.

The book, which is now available in translation, shows no sign of these difficulties, and the treatment has preserved throughout Sommerfeld's characteristic clarity of approach and his emphasis on physical principles. He follows Boltzmann rather than Gibbs, even to the point of having to resort to the DarwinFowler contour integration method in the derivation of Fermi-Dirac and Bose-Einstein statistics in order to cope with the combinatorial difficulties. To the reviewer, who was introduced in Sommerfeld's lectures to the beauty and simplicity of the method of the grand canonical ensemble, this is a source for regret. It is clear from the author's preface as well as from the note by the editors that Sommerfeld himself was not satisfied with this section and might have intended to change it if he had had the opportunity to do so.

The treatment starts with thermodynamics as a logically independent subject and only later reaches statistical mechanics by way of the elementary kinetic theory of gases, an order which is not only the historical but also the simplest one logically if perhaps not deductively.

Chapter 4, which deals with the general principles of statistical mechanies, is perhaps the least satisfactory for the reasons already stated.

Chapter 5 gives an outline of an exact kinetic theory of gases and covers, in particular, transport phenomena and deviations from statistical equilibrium. This chapter, which is almost entirely due to the editors following what seemed to be Sommerfeld's intentions, is a useful addition in bringing out a very practical approach to many problems not usually covered in such books.

The book is a welcome addition to the text-books on this subject. Like the others in the series, it displays Sommerfeld's attitude of putting practical problems and their solution above abstract principles, an attitude by its nature closer to Boltzmann than to that of Gibbs.

R. E. PeIERLS

The Chemical Constitution of Natural Fats

By Prof. T. P. Hilditeh. Third edition, revised and enlarged. Pp. xix +664 . (London: Chapman and Hall, Ltd., 1956.) 95s, net.

GINCE the second edition of this book in 1947 , $O$ there has been a broadening of interest in the natural fats, which, through their number and variety, provide almost endless opportunity for systematic study. This has occurred, first, because shortages due to war and later economic factors have stimulated research for alternative fats for food and other purposes; at the same time, the development of new and more delicate methods has brought rewarding results in a field in which their introduction had become essential if further important advances in knowledge were to be made. Prof. T. P. Hilditch has thus been faced with an arduous task in incorporating the mass of new material available in the third edition of this book, and he has overcome the difficulties with much success.

The new edition naturally contains extensive additional data on the fatty-acid composition of many fats. More important, however, are the three rewritten chapters which discuss recent material advance in knowledge concerning the component glycerides, the nature of which plays a part in determining the industrial uses to which fats are put. Two other largely rewritten chapters also call for comment. The first is that which is concerned with the chemical constitution and synthesis of fatty acids, particularly of the naturally occurring unsaturated acids, and of some acids which occur rarely and in small amount. Many uncertainties are now cleared up, and some of the findings may prove of considerable importance in the biochemical understanding of fats. The second is important because in it are: presented the methods of research on fats, with particular emphasis on such newer approaches as. 